\title{
The mixed benefit of low lipoprotein $(a)$ in type 2 diabetes
}

\author{
Michel P. Hermans ${ }^{1 *}$ D, Sylvie A. Ahn² and Michel F. Rousseau ${ }^{2}$
}

\begin{abstract}
Background: Lipoprotein(a) $(\mathrm{Lp}(a))$, a variant low-density lipoprotein (LDL), is a major genetic risk factor for cardiovascular disease. It is unknown whether an inverse relationship exists between $\mathrm{Lp}(a)$ and $\beta$-cell function (BCF), as for LDL-cholesterol (LDL-C) lowering by statins.

We therefore assessedthe cardiometabolic phenotype of 340 men with type 2 diabetes mellitus (T2DM) in relation to $\mathrm{Lp}(\mathrm{a})$, focusing on BCF and hyperbolic product $[\mathrm{B} \times \mathrm{S}]$, which adjusts BCF to insulin sensitivity and secretion.

Methods: Two groups were analyzed according to $L p(a)$ quartiles $(Q)$ : a (very-)low $L p(a)(Q 1 ; n=85)$ vs a normal-to-high Lp(a) group (Q2-Q4;n= 255).

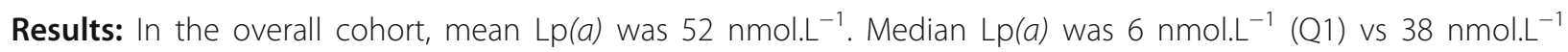
(Q2-Q4). There were no differences between groups regarding age; education; diabetes duration; body mass index; body composition and smoking. Q1 had significantly worse glycemic control, higher systolic blood pressure, more severe metabolic syndrome, and more frequent hepatic steatosis. Insulin sensitivity was significantly lower $(-37 \%)$ in Q1, who also had lesser hyperbolic product (-27\%), and higher [BxS] loss rate $(+15 \%)$. Q1 also had higher frequency $(+31 \%)$ and severity $(+20 \%)$ of atherogenic dyslipidemia. Microangiopathy and neuropathy were higher in Q1 (+ 34\% and + 48\%, respectively), whereas Q2-Q4 patients had increased macroangiopathy (+ 51\%) and coronary artery disease (CAD; $+94 \%)$.
\end{abstract}

Conclusions: Low Lp(a) appears both beneficial and unhealthy in T2DM. It is associated with unfavourable cardiometabolic phenotype, lesser BCF, poorer glycemic control, and increased microvascular damage despite being linked to markedly reduced $C A D$, suggesting that $L p(a)$-related vascular risk) follows a J-shaped curve.

Keywords: Lipoprotein(a), Diabetes, Insulin secretion, Microvascular, Atherogenic dyslipidemia, CAD

\section{Background}

In recent years, a controversy in the general media has overstated the potential risks of statins, while minimizing the cardiovascular $(\mathrm{CV})$ benefits of the class to reduce atherosclerosis. An unexpected positive aspect of this debate was a better understanding of the hyperglycemic effect of statins [1-3]. This impact, of little clinical significance, was often observed in large clinical trials, as new-onset diabetes and/or as modest depression of glycemic control in known diabetics. This hyperglycemic effect was variously ascribed to inhibition of islet 3-hydroxy-3-methylglutaryl-coenzyme A

\footnotetext{
* Correspondence: michel.hermans@diab.ucl.ac.be

'Division of Endocrinology and Nutrition, Cliniques universitaires St-Luc and Institut de Recherche Expérimentale et Clinique (IREC), Université catholique de Louvain, Avenue Hippocrate UCL 54.74, B-1200 Brussels, Belgium

Full list of author information is available at the end of the article
}

reductase, lesser peripheral insulin sensitivity (IS), and/ or decreased uptake of low-density lipoprotein cholesterol (LDL-C) by the $\beta$-cell secondary to reduction in circulating LDLs. Conversely, patients with familial hypercholesterolemia, whose baseline LDLs were exceedingly high for decades, are at lesser risk of developing type 2 diabetes mellitus (T2DM) [4].

Lipoprotein $(a)(\mathrm{Lp}(a))$ is a variant LDL covalently attached to its specific apolipoprotein Apo(a), encoded by the LPA gene. The latter determines the number of pretzel-like domain-IV duplicates, inversely correlated with $\operatorname{Lp}(a)$ number, which, as a result, is genetically determined for each individual. Although $\operatorname{Lp}(a)$ is in itself a distinct subclass within LDLs, its physiological role(s) remain(s) unknown, despite the fact that elevated $\mathrm{Lp}(a)$ 
markedly increases atherothrombosis risk and incident CVD [5-11].

While it is established that statins and/or low LDL-C levels impair insulin secretion in non-diabetic, prediabetic and T2DM subjects, it is unclear whether the same relationship exists with respect to $\operatorname{Lp}(a)$. As early as 1976, Dahlën \& Berg found that Lp(a) modulates glucose and insulin levels, observations also reported later $[5,7] . \operatorname{Lp}(a)$ was inversely associated with newonset diabetes in the general population, as shown in the Women Health and the Copenhagen City Heart studies, independent of body mass index (BMI); glycated hemoglobin $\left(\mathrm{HbA}_{1 \mathrm{c}}\right)$, or triglycerides (TG) [8], the inverse association being ascribed to lesser insulin resistance $[6,9]$.

More fundamentally, there has been no specific investigation of the relationship between $\operatorname{Lp}(a)$ and $\beta$-cell function (BCF), in particular it is unknown whether, as in the case of common LDLs, low numbers of $\mathrm{Lp}(a)$ particles are linked to $\beta$-cell function loss in T2DM. In this context, we analyzed the cardiometabolic phenotype of T2DM men in relation to $\operatorname{Lp}(a)$, focusing in particular on BCF, hyperbolic product (which adjusts BCF to insulin sensitivity (IS)), and secular loss of insulin secretion.

\section{Methods}

\section{Study design}

The study was retrospective and included 340 adult Caucasian males with T2DM, followed by the same physician and coauthor of this study (MPH) at the Cliniques universitaires St-Luc (Brussels) between January 2010 and December 2016. Exclusion criteria included patients chronically treated with medications that could substantially change IS or BCF, including systemic or topical corticosteroids, antiretroviral drugs, immunemodulatory drugs, and anti-psychotics. Were also excluded patients with chronic inflammatory diseases, cancer or major organ failure (respiratory, heart, and liver). Two groups were analyzed in parallel according to quartiles $(\mathrm{Q})$ of $\mathrm{Lp}(a)$ : a $\mathrm{Q} 1$ group $(n=85)$ vs a group combining Q2; Q3 and Q4 patients $(n=255)$.

\section{Patients characteristics}

The following socio-demographic and clinical variables were recorded: age; highest educational attainment (as proxy for socio-economic status) based on four categories: (i) secondary school with leaving certificate (no graduation); (ii) school leaving certificate (with graduation); (iii) further education, but no degree; and (iv) university degree or similar, with highest educational attainment dichotomized as lower $[(\mathrm{i})+$ (ii)] vs higher [(iii) + (iv)]; diabetes duration; presence of 1st-degree familial history (mother and/or father and/or siblings) for DM, and/or for familial history of EOCHD (early-onset coronary heart disease), defined as occurrence of a 1 st CVD event $<55$ years (men) and $<65$ years (women), with the exclusion of familial hypercholesterolemia; smoking history; and habitual ethanol intake. Hypertension prevalence was defined as systolic blood pressure (BP) $\geq 140 \mathrm{mmHg}$ and/or diastolic $\mathrm{BP} \geq 90 \mathrm{mmHg}$ and/ or current treatment with BP-lowering drug(s) prescribed for treating high BP.

Weight, height, and body mass index (BMI) were determined, together with body fat and skeletal muscle mass (BodyFat Analyzer, Omron BF 500; Omron Healthcare Europe B.V., Hoofddorp, The Netherlands). Waist circumference and conicity index were determined as surrogates for central/upper body adiposity (conicity index: waist circumference $(\mathrm{m}) / 0.109 \sqrt{[\text { weight }(\mathrm{kg}) /}$ height $(\mathrm{m})]$ ). The presence of a metabolic syndrome (MetS) was defined by a score $\geq 3 / 5$ for the following items: (i) impaired fasting glucose or diabetes; (ii) hypertension; (iii) enlarged waist; (iv) hypertriglyceridemia; and (v) decreased high-density lipoprotein (HDL) cholesterol, according to the IDF-NHLBI-AHA-WHF-IAS-IASO harmonized definition [12]. Non-alcoholic fatty liver (NAFL) was based on the finding on abdominal ultrasonography by a trained radiologist of hepatorenal echo contrast and liver brightness, in the absence of etiological factors associated with liver steatosis, including excess ethanol intake].

Each subject underwent non-invasive combined assessment of BCF and -IS using the Homeostasis Model Assessment (HOMA-2, computer-based, version: http:// www.dtu.ox.ac.uk), from triplicates means of fasting glucose and specific insulin levels obtained after an overnight fast and discontinuation of all glucose-lowering or glucose-sensitizing therapies for $24 \mathrm{~h}(48 \mathrm{~h}$ in case of insulin glargine and long-acting sulfonylureas and 2-28 days in case of GLP-1-RA with short/long duration of action). For patients treated with pioglitazone, HOMA was performed prior to introduction of this long-acting insulinsensitizer $[13,14]$.

Values of insulin secretory capacity ([B]; normal value $100 \%$ ) were plotted as a function of IS ([S]; normal value $100 \%)$, defining a hyperbolic product area $[\mathrm{B} \times \mathrm{S}]$ (unit: $\%^{2}$; normal: $100 \%$, corresponding to $10^{4} \%^{2}$ ), representing the true, underlying $\mathrm{BCF}$. $[\mathrm{BxS}]$ loss over a subject's lifespan (ie. the secular loss of hyperbolic product ([BxS] loss rate; \%.year ${ }^{-1}$ ) was obtained by dividing the absolute loss of $[\mathrm{BxS}]$ already incurred, the value of which corresponds to $100 \%$ - current [BxS] value (\%), by a subjects' age (year) at the time of HOMA-modeling. This simple formula (100\%-[BxS])/ age) provides an estimate of annual $[\mathrm{BxS}]$ loss rate, based on the assumptions that (i) any newborn subject, including those who develop T2DM later, starts its life 
with a $[\mathrm{BxS}]$ value of $100 \%$ conferring normal carbohydrate homeostasis, and (ii) that the loss of $[\mathrm{BCF}]$ is, for the most part, linear over the years $[15,16]$.

\section{Ongoing therapies and comorbidities}

Current medications were recorded: glucose-lowering drugs (metformin; sulfonylureas/glinides; pioglitazone; dipeptidyl peptidase-4 inhibitors (DPP-4-I); glucagonlike peptide-1 receptor agonists (GLP-1-RA); insulin); and $\mathrm{CV}$ drugs [BP-lowering agents; aspirin (as antiplatelet agent); lipid-modifying drugs (LMD): statins; fibrates and/or ezetimibe]. Estimated glomerular filtration rate (eGFR) was calculated using the Modification of Diet in Renal Disease equation [17]. Normo, microalbuminuria and macroalbuminuria were defined as urinary albumin excretion < 30 (normo-), 30-299 (micro-) and $\geq 300 \mu \mathrm{g} . \mathrm{mg}$ creatinine ${ }^{-1} .1 .73 \mathrm{~m}^{2}$ (macro-), from first-morning urine sample. Diabetic retinopathy and nephropathy were defined using ICD-9-CM diagnoses and procedure codes. The presence of a peripheral neuropathy was based on clinical examination (knee and ankle reflexes; Semmes-Weinstein monofilament test) and/or electromyography. Eye visual examinations by an experienced ophthalmologist and/or fluorescein angiography were performed to diagnose retinopathy.

Coronary artery disease (CAD) diagnosis was based on medical history (myocardial infarction, angioplasty, stenting, revascularization surgery and/or significant coronary stenosis confirmed by angiography), systematic review of all procedures, and/or screening (exercise testing; echocardiography; magnetic resonance imaging; or other subclinical disease imaging techniques). Cerebrovascular disease was defined as a history of stroke ( $U K$ Prospective Diabetes Study criteria: any neurological deficit $\geq 1$ month, without distinction between ischemic, embolic and haemorrhagic events) and/or transient ischaemic attack [18]. Peripheral artery disease (PAD) was defined by a medical history of lower-limb(s) claudication and/or clinical or imaging evidence for ischemic diabetic foot, angioplasty, stenting, revascularization surgery and/or lower-limb artery stenosis at Doppler ultrasonography and/or angiography.

\section{Laboratory values}

$\mathrm{HbA}_{1 \mathrm{c}}$; fasting lipids (total cholesterol (C), HDL-C, triglycerides; LDL-C (computed using Friedewald's formula), $\mathrm{Lp}(a)$, and non-HDL-C (by subtracting HDL-C from total $\mathrm{C}$ )); apolipoproteins $\mathrm{A}-\mathrm{I}$ (apoA-I) and $\mathrm{B}_{100}$ $\left(\mathrm{apoB}_{100}\right)$; ${ }_{\mathrm{hs}} \mathrm{CRP}$; thyroid-stimulating hormone (TSH); serum total and free testosterone; sex hormone-binding globulin (SHBG); and albuminuria were determined by routine methods. Total cholesterol and TG were determined using SYNCHRON ${ }^{\circ}$ system (Beckman Coulter Inc., Brea, CA). HDL-C was determined with ULTRA-
$\mathrm{N}$-geneous reagent (Genzyme Corporation, Cambridge, MA). ApoA-I and $\mathrm{apoB}_{100}$ were determined with immunonephelometry on BNII Analyzer (Siemens Healthcare Products $\mathrm{GmbH}$, Marburg (Germany). Lp(a) concentration was determined by turbidimetric analysis of fresh plasma samples (Tina-quant Lipoprotein(a) Gen. 2 on Cobas c 502 module analyzer (Roche Diagnostics SA, Rotkreuz (Switzerland); measurement range: 7-240 nmol/ $\mathrm{L}$, regardless of isoforms; threshold value for $\mathrm{Lp}(a)$-related $\mathrm{CV}$ risk increase $>75 \mathrm{nmol} / \mathrm{L})$. Mean $(\mathrm{SD})$ local reference values for $\operatorname{Lp}(a)$ obtained from a group of 50 healthy Caucasian male volunteers were 40 (37) nmol.L ${ }^{-1}$ (median 26 [IQR 10-72] nmol. $\mathrm{L}^{-1}$; range 7-124 nmol. $\mathrm{L}^{-1}$ ).

Atherogenic dyslipidemia (AD) was defined as the combination of low HDL-C $\left(<40 \mathrm{mg} \cdot \mathrm{dL}^{-1}\right)$ and high fasting TG $\left(\geq 150 \mathrm{mg} \cdot \mathrm{dL}^{-1}\right)$ based on the MetS definition's cutoffs for non-LDL lipids. AD prevalence, was established from the combined occurrence of low HDL$C$ plus high TG, from last available fasting TG and HDL-C measurements prior to LMD implementation $[\mathrm{LMD}(\mathrm{s})$-treated patients], or from current fasting TG and HDL-C [LMD-naïve patients], respectively. AD severity was quantified as continuous variable using $\log (\mathrm{TG}) / \mathrm{HDL}-\mathrm{C}$ ratio $[19,20]$.

Results are presented as means $( \pm 1$ standard deviation (SD)) or as median [interquartile range (IQR)]. The significance of differences between means was assessed by Student's $t$ test or by alternate Welch's test for data sets with significant differences in SDs, and by Fisher's Exact test for differences in proportions. Results were considered significant or non-significant (NS) for $\mathrm{p}<$ or $\geq 0.05$ respectively.

\section{Results}

\section{Patients characteristics}

There were no differences between Q1 and Q2-4 patients regarding age; education (lower vs higher: $45 \%$ vs $55 \%(\mathrm{Q} 1)$ and $44 \%$ vs $56 \%(\mathrm{Q} 2-4))$; diabetes duration; family history (DM and/or EOCHD); and smoking (Table 1). Habitual ethanol intake and self-reported leisure-time physical activity were also similar between groups (not shown). Glycemic control was on average above target, with mean $\mathrm{HbA}_{1 \mathrm{c}}$ in the overall population at 59 (11) mmol.mol ${ }^{-1}$. Q1 patients had significantly worse glycemic control, at 61 (13) vs. 58 (10) mmol.mol ${ }^{-1}$ in Q2-4 (p 0.0276). Patients were predominantly obese in the overall study population, with central adiposity. There were no differences between groups in terms of BMI, waist circumference, body composition (fat mass, visceral fat and skeletal muscle mass), and adiposity distribution (conicity index). Systolic BP was higher (by an average $5 \mathrm{mmHg}$ ) in Q1 patients, in whom the prevalence of hypertension was increased by $10 \%$, and close to $100 \%$. The prevalence of 
Table 1 Patients characteristics

\begin{tabular}{|c|c|c|c|c|}
\hline & & 1st Quartile Lp(a) & Quartiles 2-4 Lp(a) & $P$ \\
\hline$n$ & & 85 & 255 & $\sim$ \\
\hline age & years & $68(10)$ & $67(12)$ & NS \\
\hline diabetes duration & years & $18(9)$ & $16(9)$ & NS \\
\hline $\mathrm{HbA}_{1 \mathrm{c}}$ & mmol.mol ${ }^{-1}$ & $61(13)$ & $58(10)$ & 0.0276 \\
\hline diabetes family history & $\%$ & 48 & 50 & NS \\
\hline EOCHD family history & $\%$ & 12 & 10 & NS \\
\hline smoking $^{\mathrm{a}}$ & & $35-46-19$ & $33-49-18$ & NS \\
\hline hypertension & $\%$ & 98 & 89 & 0.0140 \\
\hline systolic blood pressure & $\mathrm{mm} \mathrm{Hg}$ & $144(21)$ & $139(19)$ & 0.0416 \\
\hline body mass index & $\mathrm{kg} \cdot \mathrm{m}^{-2}$ & $29.0(5.0)$ & $28.8(5.3)$ & NS \\
\hline waist circumference & $\mathrm{cm}$ & $105(13)$ & $105(14)$ & NS \\
\hline fat mass & $\%$ & $26.7(6.0)$ & $25.9(6.1)$ & NS \\
\hline visceral fat & 0-30 score & $14(4)$ & $14(5)$ & NS \\
\hline skeletal muscle mass & $\%$ & $32.9(2.8)$ & $33.2(3.1)$ & NS \\
\hline conicity index & $\mathrm{m}^{2} \cdot \mathrm{kg}^{-1}$ & $1.36(0.07)$ & $1.36(0.08)$ & NS \\
\hline \multirow[t]{2}{*}{ metabolic syndrome } & $\%$ & 86 & 80 & NS \\
\hline & $0 / 5$ to $5 / 5$ & $3.9(1.1)$ & $3.6(1.1)$ & 0.0301 \\
\hline hepatic steatosis & $\%$ & 92 & 69 & $<0.0001$ \\
\hline
\end{tabular}

MetS was high and similar in both groups; however, Q1 patients had higher MetS severity score (8\% relative increase). They also had a markedly increased frequency of non-alcoholic hepatic steatosis (33\% relative increase).

\section{Cardiometabolic phenotype}

For all patients, mean insulin sensitivity was lowered (56\% of normal), indicative of substantial insulin resistance (Table 2). Fasting insulinaemia was higher (by $36 \%)$ in Q1 patients, whose insulin sensitivity was

Table 2 Cardiometabolic phenotype \& therapies

\begin{tabular}{|c|c|c|c|c|}
\hline & & 1st Quartile Lp(a) & Quartiles 2-4 Lp(a) & $P$ \\
\hline$n$ & & 85 & 255 & $\sim$ \\
\hline insulinaemia & pmol...-1 & $136(93)$ & $100(70)$ & 0.0014 \\
\hline insulin sensitivity & $\%$ & $40(26)$ & $62(43)$ & $<0.0001$ \\
\hline hyperbolic product [B × S] & $\%$ & $22(15)$ & $30(20)$ & $<0.0001$ \\
\hline$[\mathrm{B} \times \mathrm{S}]$ loss rate & $\% . y r^{-1}$ & $1.46(0.65)$ & $1.27(0.49)$ & 0.0149 \\
\hline$\beta C S$ - metformin - TZD & $\%$ & $37-76-7$ & $45-71-3$ & NS \\
\hline DDP-4-I / GLP-1-RA & $\%$ & 15 & 29 & 0.0100 \\
\hline \multirow[t]{2}{*}{ insulin } & $\%$ & 56 & 43 & 0.0442 \\
\hline & IU.day ${ }^{-1} \cdot \mathrm{kg}^{-1}$ & $0.94(0.86)$ & $0.70(0.44)$ & NS \\
\hline ACE-I - ARB & $\%$ & $44-34$ & $36-28$ & NS \\
\hline$C C B$ - BB - diuretic & $\%$ & $33-34-46$ & $29-42-34$ & NS \\
\hline aspirin & $\%$ & 55 & 54 & NS \\
\hline anti-dyslipidemic drug(s) & $\%$ & 86 & 85 & NS \\
\hline statin - ezetimibe & $\%$ & $76-13$ & $81-13$ & NS \\
\hline fenofibrate & $\%$ & 36 & 19 & 0.0045 \\
\hline
\end{tabular}

Results are expressed as means (1 SD) or proportions (\%). ACE-I angiotensin-converting enzyme inhibitor ARB angiotensin II type -1 receptor (AT1) blocker, $\beta C S$ beta-cell stimulant, $B B$ beta-blockers, $C C B$ calcium-channel blocker, DPP-4-I dipeptidyl peptidase type 4 inhibitor, GLP-1-RA glucagon-like peptide 1 receptor agonist, $L p(a)$ lipoprotein(a), TZD thiazolidinedione, NS not significant 
significantly lower (by a relative 37\%) compared to Q2-4 patients $(p<0.0001)$. In the general cohort, the hyperbolic product $([\mathrm{BxS}]$; a measure of residual $\beta$ cell function) was markedly reduced (28.1\%), the mean annual loss of $[\mathrm{BxS}]$ being $1.32 \%$.

This hyperbolic product was further reduced in Q1 patients, whose residual $\beta$-cell function was decreased by $8 \%$ (absolute) and by $27 \%$ (relative) compared to Q2-4 patients. $[\mathrm{BxS}]$ loss rate was significantly more severe in Q1 patients $\left(1.46 \%\right.$ year $^{-1}$ ), ie a $15 \%$ faster loss rate (relative value).

With respect to glucose-lowering therapies, Q1 patients were significantly less often treated with incretinbased therapies, and more often $(+30 \%)$ treated with insulin. There were no differences between groups regarding metformin, $\beta$-cell stimulant and/or glitazone use. CV medications were used in similar proportions in the 2 groups, except for a markedly increased use of fenofibrate (+ $89 \%)$ by Q1 patients (Table 2 ).

\section{Lipids and lipoproteins}

Table 3 shows the lipids and lipoproteins values of the Q1 and Q2-4 groups. For the overall cohort, mean $\mathrm{Lp}\left(\right.$ a) was 52 (73) nmol.L $\mathrm{L}^{-1}$ (median $24 \mathrm{nmol.L} \mathrm{L}^{-1}$; IQR

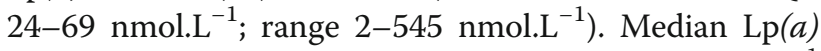
values were $6(\mathrm{Q} 1) ; 11(\mathrm{Q} 2) ; 38(\mathrm{Q} 3)$; and $120 \mathrm{nmol. \textrm {L } ^ { - 1 }}$ (Q4). More than $3 / 4$ of the overall cohort had normal $\mathrm{Lp}(a)$, ie $<75 \mathrm{nmol.} \mathrm{L}^{-1}$; a cutoff corresponding to the 78th percentile of the overall cohort. Median $\operatorname{Lp}(a)$ in Q2-4 patients was $38 \mathrm{nmol} . \mathrm{L}^{-1}$, which means that Q1 patients had median $\operatorname{Lp}(a)$ more than 6-fold lower than the median value for the 3 upper Qs.

LDL-C level was significantly higher in Q2-4 (+ 13\%), whereas total $\mathrm{C}$; non-HDL-C; HDL-C; $\mathrm{apoB}_{100}$ and
apoA-I levels were similar in the 2 groups. LDL size, estimated by the LDL-C/apoB $B_{100}$ ratio, was significantly reduced $(-8 \%)$ in Q1 patients, in whose both the frequency $(+31 \%)$ and severity $(+20 \%$ of $\log (\mathrm{TG}) / \mathrm{HDL}-$ C) of AD were significantly increased (Table 3). Regarding non-lipid laboratory values, there were no differences between groups with respect to ${ }_{\mathrm{hs}} \mathrm{CRP}$; SHBG; total and free testosterone; and TSH (not shown). In a multiple regression analysis taking into account potentially confounders of $\mathrm{Lp}(a)$ and glycemic/metabolic control (age; duration of diabetes, glomerular filtration rate; BMI; sedentarity; waist; insulin resistance; atherogenic dyslipidemia; $\mathrm{HbA}_{1 \mathrm{c}}$ ), no relationship was found but for a very modest effect of age $\left(r^{2}=0.0121 ; p 0.039\right)$.

\section{Comorbidities}

Damage to target organs is described in Table 4. Overall microangiopathy was markedly and significantly more prevalent in Q1 patients (+34\%), with microangiopathy frequencies within Q2 to Q4: 39\% (Q2); 49\% (Q3), and $52 \%$ (Q4; NS for trend). Retinopathy frequency was increased by $20 \%$ in Q1 relative to Q2-4, although the difference did not reach significance. Of all the quartiles, Q2 patients had the lowest prevalence in microangiopathies, and were on par with Q1 with respect to lower rates of overall macroangiopathy. Q1 patients had a significantly increased prevalence of neuropathy $(+48 \%)$ vs the frequencies within Q2 to Q4: 18\% (Q2); 28\% (Q3); and $31 \%(\mathrm{Q} 4 ; \mathrm{p}$ NS for trend). There was no difference between groups with regard to eGFR and (micro)albuminuria prevalence or severity. On the other hand, for large vessels, Q2-4 patients showed a markedly increased prevalence in overall macroangiopathy $(+51 \%$ relative; $+15 \%$ absolute), more specifically $\mathrm{CAD}$, which

Table 3 Lipids \& lipoproteins

\begin{tabular}{|c|c|c|c|c|}
\hline & & 1st Quartile Lp(a) & Quartiles 2-4 Lp(a) & $P$ \\
\hline$n$ & & 85 & 255 & $\sim$ \\
\hline lipoprotein(a) mean (SD) & nmol.. $\mathrm{L}^{-1}$ & $7(2)$ & $68(78)$ & $\sim$ \\
\hline lipoprotein(a) median [IQR] & $\mathrm{nmol.} \mathrm{L}^{-1}$ & $6[5-8]$ & 38 [15-84] & $\sim$ \\
\hline cholesterol & $m g \cdot d L^{-1}$ & $150(34)$ & $155(33)$ & NS \\
\hline non-HDL-C & $m g \cdot d L^{-1}$ & $106(36)$ & $109(33)$ & NS \\
\hline LDL-C & $m g \cdot d L^{-1}$ & $70(29)$ & $79(28)$ & 0.0114 \\
\hline $\mathrm{apoB}_{100}$ & $m g \cdot d L^{-1}$ & $82(23)$ & $84(21)$ & NS \\
\hline LDL-C. apoB ${ }_{100}^{-1}$ & & $0.87(0.28)$ & $0.95(0.25)$ & 0.0207 \\
\hline triglycerides & $m g \cdot d^{-1}$ & 199 (194) & $154(105)$ & 0.0394 \\
\hline HDL-C & $m g \cdot d^{-1}$ & 44 (15) & $46(14)$ & NS \\
\hline apoA-I & $m g \cdot d L^{-1}$ & $139(30)$ & $143(23)$ & NS \\
\hline atherogenic dyslipidemia & $\%$ & 59 & 45 & 0.0332 \\
\hline $\log (T G) \cdot H D L-C^{-1}$ & & $0.06(0.03)$ & $0.05(0.02)$ & 0.0324 \\
\hline
\end{tabular}

Results are expressed as means (1 SD), medians [interquartile range (IQR)], or proportions (\%). apo apolipoprotein, C cholesterol, $H D L$ high-density lipoprotein, LDL low-density lipoprotein, $L p(a)$ lipoprotein(a), TG triglycerides, NS not significant 
Table 4 Cardiovascular complications

\begin{tabular}{|c|c|c|c|c|}
\hline & & 1st Quartile Lp(a) & Quartiles 2-4 Lp(a) & $P$ \\
\hline$n$ & & 85 & 255 & $\sim$ \\
\hline microangiopathy & $\%$ & 62.4 & 46.7 & 0.0127 \\
\hline retinopathy & $\%$ & 27.1 & 22.5 & NS \\
\hline peripheral polyneuropathy & $\%$ & 37.6 & 25.4 & 0.0376 \\
\hline eGFR & $\mathrm{mL} \cdot \mathrm{min}^{-1} .1 .73 \mathrm{~m}^{2}$ & $76(25)$ & $75(27)$ & NS \\
\hline albuminuria & mg.g creatinine- ${ }^{1}$ & $200(497)$ & $107(357)$ & NS \\
\hline normo - micro - macroalbuminuria & $\%$ & $56-30-14$ & $63-28-9$ & NS \\
\hline macroangiopathy & $\%$ & 29.4 & 44.3 & 0.0158 \\
\hline coronary artery disease & $\%$ & 17.6 & 34.1 & 0.0040 \\
\hline cerebrovascular disease & $\%$ & 8.2 & 9.0 & NS \\
\hline peripheral artery disease & $\%$ & 8.2 & 11.8 & NS \\
\hline
\end{tabular}

Results are expressed as means (1 SD) or proportions (\%). eGFR estimated glomerular filtration rate, Lp(a) lipoprotein(a), NS not significant

was increased by $+94 \%$ (relative) and $+17 \%$ (absolute). Overall macroangiopahy frequencies within Q2 to Q4 were: 29\% (Q2); 52\% (Q3), and 52\% (Q4; p for trend 0.0034 ), with CAD prevalence of $20 \%$ (Q2); $40 \%$ (Q3); and $42 \%$ (Q4; p for trend 0.0021).

\section{Discussion}

The work aimed to determine whether T2DM patients with low $\operatorname{Lp}(a)$ have a variant phenotype, beyond the expectation of lesser risk of macrovascular damage. To do this, we compared patients with low to very-low $\operatorname{Lp}(a)$ (Q1) to a group of patients with normal (Q2 and Q3) or elevated (Q4) $\operatorname{Lp}(a)$. Our results show that low $\operatorname{Lp}(a)$ is associated with a specific cardiometabolic phenotype, combining higher systolic BP and hypertension; poorer glycemic control; greater microangiopathy and neuropathy frequency; and lesser macrovascular disease. They also had a more severe MetS score, and more frequent liver steatosis, the latter associated with hyperinsulinemia; AD prevalence, and smaller-denser LDLs.

Concerning carbohydrate homeostasis, Q1 patients were characterized by greater insulin resistance, poorer insulin secretion, and more pronounced BCF loss. Thenceforth, it is hardly surprising that more of them could not stay on oral glucose-lowering drugs only and were switched to insulin. These differences in glucose homeostasis are likely determinants of poorer glycemic control in (very) low $\operatorname{Lp}(a)$ patients, as diabetes duration was similar between groups.

As regards the increased prevalence of microangiopathy in (very) low $\operatorname{Lp}(a)$ patients, it is unlikely that it stemmed directly from the low level of the lipoprotein, based on the current paradigm of diabetic microvascular disease [21]. On the other hand, at least four aspects of the unfavorable cardiometabolic phenotype associated with low $\operatorname{Lp}(a)$ may have contributed to the genesis (or aggravation) of small vessel damage, namely (i) poorer glycemic control; (ii) higher BP; (iii) greater MetS score; and (iv) more prevalent and severe AD [19, 20, 22-25].

As expected, overall macroangiopathy, including CAD, was significantly more frequent in patients with higher $\mathrm{Lp}(a)$, consistent with previous transversal or longitudinal studies in diabetic $[10,11]$ and non-diabetic patients [26-28]. Macroangiopathy prevalence increased already in the $3^{\text {rd }}$ quartile, suggesting enhanced vulnerability of large vessels at modestly high $\mathrm{Lp}(a)$ levels in diabetes. All this implies relativizing the current "normality" threshold for $\operatorname{Lp}(a)$ in diabetics. Regarding microvascular risk, it is rather linked to having a low (rather than a high) $\mathrm{Lp}(a)$, with "normality" thereby considered beyond Q1. In contrast, the risk to large vessels appears linear over quartiles, with a marked increase in complications from Q3 onwards. As the median $\operatorname{Lp}(a)$ value of Q3 patients was well below the pathological threshold for non-diabetics $\left(\geq 75\right.$ nmol. $\left.\mathrm{L}^{-1}\right)$, it seems obvious that the macrovascular cutoff should be revised downwards in T2DM. If one takes the vascular system as a whole (all vessel sizes combined), it becomes clear that the risk linked to $\operatorname{Lp}(a)$ in diabetes follows a J curve that is conditional on the size of the vessels involved, with a rise in small vessels risk at (very) low levels, and, as expected, higher macrovascular risk (especially CAD) at increasing $\operatorname{Lp}($ a) levels.

The study population was exclusively male and Caucasian, which restricts the applicability of our findings in terms of gender and ethnicity. Another limitation of this study is related to the transverse design, which does not formally establish the direction of causality of the reported associations. The lack of association between $\mathrm{Lp}$ (a) levels and a series of cardiometabolic variables in multiple regression analysis is consistent with literature data showing that few non-genetic/acquired determinants are able to influence Lp(a) level in a given individual, with the exception of severe renal impairment or certain drugs, 
such as niacin or proprotein convertase subtilisin/kexin type 9 inhibitors. Thus, the stability of $\operatorname{Lp}(a)$ level over time is such that the observed associations are likely to be linked to $\operatorname{Lp}(a)$, and not that $\mathrm{Lp}(a)$ levels would have been modulated by an unfavorable phenotype or the presence of vascular complications.

\section{Conclusions}

Having a low level of $\operatorname{Lp}(a)$ appears both beneficial and unhealthy in T2DM. At the microvascular level, a low rate is associated with lesser $ß$-cell function, poorer glycemic control, and increased microvascular damage and neuropathy. On the other hand, the same low level of $\mathrm{Lp}(a)$ is associated, as in the general population, with a reduced prevalence of macrovascular disease, despite a less favorable cardiometabolic phenotype. This suggests that the overall vascular risk associated with $\operatorname{Lp}(a)$ follows a J-shaped curve in the particular T2DM population when the vascular system is being studied as a global target organ, all sizes of vessels combined.

\section{Abbreviations}

AD: Atherogenic dyslipidemia; ApoA-I: Apolipoprotein A-l; apoB: apolipoprotein $B_{100}$; [B]: HOMA-measured BCF; BCF: $\beta$-cell function; BMI: Body mass index; BP: Blood pressure; $[\mathrm{BxS}]$ : Hyperbolic product between $\beta$-cell function and IS; C: Cholesterol; CAD: Coronary artery disease; CHD: Coronary heart disease; CRP: C-reactive protein; CV: Cardiovascular; CVD: Cardiovascular disease; DM: Diabetes mellitus; DPP4-I: Dipeptidyl peptidase-4 inhibitor; eGFR: Estimated glomerular filtration rate; EOCHD: Early-onset CHD; GLP-1-RA: Glucagon-like peptide-1 receptor agonist; $\mathrm{HbA}_{1}$ : Glycated hemoglobin; HDL: High-density lipoprotein; HDL-C: Highdensity lipoprotein cholesterol; HOMA: Homeostasis model assessment; IS: Insulin sensitivity; LDL: Low-density lipoprotein; LDL-C: Low-density lipoprotein cholesterol; LMD: Lipid-modifying drug; Lp(a): Lipoprotein(a); MetS: Metabolic syndrome; NAFL: Non-alcoholic fatty liver; non-HDL-C: nonhigh-density lipoprotein cholesterol; NS: Non-significant; PAD: Peripheral artery disease; Q: Quartile; [S]: HOMA-measured insulin sensitivity; SD: Standard deviation; SHBG: Sex hormone-binding globulin; T2DM: Type 2 diabetes mellitus; TG: Triglycerides (triacylglycerols); TSH: Thyroid- stimulating hormone

\section{Acknowledgments}

Not applicable.

\section{Funding}

This study received no financial support.

\section{Availability of data and materials}

Data are available at the Division of Endocrinology \& Nutrition, Cliniques universitaires St-Luc and Institut de Recherche Expérimentale et Clinique (IREC), Université catholique de Louvain, Brussels (Belgium) (person of contact: Prof MP Hermans).

\section{Authors' contributions}

All authors contributed equally to the manuscript. All authors read and approved the final version of the manuscript, and gave their consent for publication.

\section{Author's information}

Not applicable.

\section{Ethics approval and consent to participate}

The study protocol was approved by the Commision d'Ethique Biomédicale Hospitalo-facultaire de l'Université catholique de Louvain (Bruxelles) 2009/ 20avr/141 reg N B4032009/6275. All patients agreed that their clinical record data be used for retrospective study purposes.

Consent for publication

Not applicable.

Competing interests

The authors declare that they have no competing interests.

\section{Publisher's Note}

Springer Nature remains neutral with regard to jurisdictional claims in published maps and institutional affiliations.

\section{Author details}

${ }^{1}$ Division of Endocrinology and Nutrition, Cliniques universitaires St-Luc and Institut de Recherche Expérimentale et Clinique (IREC), Université catholique de Louvain, Avenue Hippocrate UCL 54.74, B-1200 Brussels, Belgium.

${ }^{2}$ Division of Cardiology, Cliniques universitaires St-Luc and Pôle de Recherche Cardiovasculaire, Institut de Recherche Expérimentale et Clinique (IREC),

Université catholique de Louvain, Brussels, Belgium.

Received: 9 May 2017 Accepted: 4 September 2017

Published online: 12 September 2017

References

1. Chan DC, Pang J, Watts GF. Pathogenesis and management of the diabetogenic effect of statins: a role for adiponectin and coenzyme Q10. Curr Atheroscler Rep. 2015;17:472.

2. Hermans MP, Ahn SA, Rousseau MF. Effect of lipid management on coronary heart disease risk in patients with diabetes. Diabetes in cardiovascular disease: a companion to Braunwald's heart disease. Editors: Darren K. McGuire \& Nikolaus Marx. Philadelphia: Elsevier Saunders 2015; pp 181-202.

3. Betteridge DJ, Carmena R. The diabetogenic action of statins - mechanisms and clinical implications. Nat Rev Endocrinol. 2016;12:99-110.

4. Besseling J, Kastelein JJ, Defesche JC, Hutten BA, Hovingh GK. Association between familial hypercholesterolemia and prevalence of type 2 diabetes mellitus. JAMA. 2015;313:1029-36.

5. Dahlën $G$, Berg K. Confirmation of an influence of the inherited Lp(a) variation on serum insulin and glucose levels. Clin Genet. 1979;16:418-27.

6. Haffner SM, Karhapaa P, Rainwater DL, Mykkanen L, Aldrete G Jr, Laakso M. Insulin sensitivity and Lp(a) concentrations in normoglycemic men. Diabetes Care. 1995;18:193-9.

7. Paige E, Masconi KL, Tsimikas S, Kronenberg F, Santer P, Weger S, Willeit J, Kiechl S, Willeit P. Lipoprotein(a) and incident type-2 diabetes: results from the prospective Bruneck study and a meta-analysis of published literature. Cardiovasc Diabetol. 2017;16:38.

8. Mora S, Kamstrup PR, Rifai N, Nordestgaard BG, Buring JE, Ridker PM. Lipoprotein(a) and risk of type 2 diabetes. Clin Chem. 2010;56:1252-60.

9. Boronat M, Saavedra P, Pérez-Martín N, López-Madrazo MJ, Rodríguez-Pérez C, Nóvoa FJ. High levels of lipoprotein(a) are associated with a lower prevalence of diabetes with advancing age: results of a cross-sectional epidemiological survey in Gran Canaria Spain. Cardiovasc Diabetol. 2012;11:81.

10. Qi Q, Qi L. Lipoprotein(a) and cardiovascular disease in diabetic patients. Clin Lipidol. 2012;7:397-407.

11. Lim TS, Yun JS, Cha SA, Song KH, Yoo KD, Ahn YB, Park YM, Ko SH. Elevated lipoprotein(a) levels predict cardiovascular disease in type 2 diabetes mellitus: a 10-year prospective cohort study. Korean J Intern Med. 2016;31:1110-9.

12. Alberti KG, Eckel RH, Grundy SM, Zimmet PZ, Cleeman JI, Donato KA, Fruchart JC, James WP, Loria CM, Smith SC Jr, International Diabetes Federation Task Force on Epidemiology and Prevention; National Heart, Lung, and Blood Institute; American Heart Association; World Heart Federation; International Atherosclerosis Society; International Association for the Study of Obesity. Harmonizing the metabolic syndrome: a joint interim statement of the international diabetes federation task force on epidemiology and prevention; National Heart, Lung, and Blood Institute; American Heart Association; world heart federation; international atherosclerosis society; and International Association for the Study of obesity. Circulation. 2009;120:1640-5. 
13. Hermans MP, Levy J, Morris RJ, Turner RC. Comparison of insulin sensitivity tests across a range of glucose tolerance from normal to diabetes. Diabetologia. 1999;42:678-87.

14. Hermans MP, Levy J, Morris RJ, Turner RC. Comparison of tests of beta-cell function across a range of glucose tolerance from normal to diabetes. Diabetes. 1999:48:1779-86.

15. Hermans MP. Diabetic macro- and microvascular disease in type 2 diabetes. Diabetes Vasc Dis Res. 2007;4:S7-11.

16. Munoko T, Hermans MP. Phenotypic characterization of first generation Maghrebian migrants with type 2 diabetes: a gender-based comparison with a reference north-Caucasian Belgian cohort. Diab Met Syndr. 2008:2:115-24.

17. Levey AS, Bosch JP, Lewis JB, Greene T, Rogers N, Roth D. A more accurate method to estimate glomerular filtration rate from serum creatinine: a new prediction equation. Modification of diet in renal disease study group. Ann Intern Med. 1999;130:461-70.

18. Stevens RJ, Coleman RL, Adler Al, Stratton IM, Matthews DR, Holman RR UKPDS 66: risk factors for myocardial infarction case fatality and stroke case fatality in type 2 diabetes. Diabetes Care. 2004;27:201-7.

19. Hermans MP, Ahn SA, Rousseau MF. Log(TG)/HDL-C is related to both residual cardiometabolic risk and ?-cell function loss in type 2 diabetes males. Cardiovasc Diabetol. 2010:9:88.

20. Hermans MP, Ahn SA, Rousseau MF. The atherogenic dyslipidemia ratio $[\log (\mathrm{TG}) / \mathrm{HDL}-\mathrm{C}]$ is associated with residual vascular risk, $\beta$-cell function loss and microangiopathy in type 2 diabetes females. Lipids Health Dis. 2012;11:132

21. Brownlee M. The pathobiology of diabetic complications: a unifying mechanism. Diabetes. 2005:54:1615-25.

22. Hermans MP, Ahn SA, Amoussou-Guenou KD, Rousseau MF. Impact of metabolic syndrome on microvascular complications in type 2 diabetes. Diab Metab Syndr. 2010;4:150-4.

23. Hermans MP, Amoussou-Guenou KD, Bouenizabila E, Sadikot SS, Ahn SA, Rousseau MF. Size, density and cholesterol load of HDL predict microangiopathy, coronary artery disease and $\beta$-cell function in men with T2DM. Diabetes Metab Syndr. 2016 Sep 1; doi:10.1016/j.dsx.2016.08.029. [Epub ahead of print]

24. Sacks FM, Hermans MP, Fioretto P, Valensi P, Davis T, Horton E, Wanner C, Al-Rubeaan K, Aronson R, Barzon I, Bishop L, Bonora E, Bunnag P, Chuang LM, Deerochanawong C, Goldenberg R, Harshfield B, Hernández C, Herzlinger-Botein S, Itoh H, Jia W, Jiang YD, Kadowaki T, Laranjo N, Leiter L, Miwa T, Odawara M, Ohashi K, Ohno A, Pan C, Pan J, Pedro-Botet J, Reiner Z, Rotella CM, Simo R, Tanaka M, Tedeschi-Reiner E, Twum-Barima D, Zoppini G, Carey VJ. Association between plasma triglycerides and highdensity lipoprotein cholesterol and microvascular kidney disease and retinopathy in type 2 diabetes mellitus: a global case-control study in 13 countries. Circulation. 2014;129:999-1008.

25. Hermans MP, Fruchart J-C, Davignon J, Al-Rubeaan K, Amarenco P, Assmann G, Barter P, Betteridge J, Bruckert E, Chapman MJ, Cuevas A, Farnier M, Ferrannini E, Fioretto P, Genest J, Ginsberg HN, Gotto AM, Hu D, Kadowaki T, Kodama T, Krempf M, Matsuzawa Y, Nuñez-Cortes JM, Calvo Monfil C, Ogawa H, Plutzky J, Rader DJ, Reiner Z, Sadikot S, Santos RD, Shlyakhto E, Sritara P, Sy R, Tall A, Tan CE, Tokgözoglu L, Toth PP, Valensi P, Wanner C, Zambon A, Zhu J, Zimmet P. Residual microvascular risk in type 2 diabetes in 2014: is it time for a re-think? A perspective from the residual risk reduction initiative (R3i). J Diabetes Metab. 2014;5:8.

26. Berglund L, Ramakrishnan R. Lipoprotein(a): an elusive cardiovascular risk factor. Arterioscler Thromb Vasc Biol. 2004;24:2219-26.

27. Kamstrup PR, Tybjaerg-Hansen A, Steffensen R, Nordestgaard BG. Genetically elevated lipoprotein(a) and increased risk of myocardial infarction. JAMA. 2009:301:2331-9.

28. Emerging Risk Factors Collaboration, Erqou S, Kaptoge S, Perry PL, Di Angelantonio E, Thompson A, White IR, Marcovina SM, Collins R, Thompson SG, Danesh J. Lipoprotein(a) concentration and the risk of coronary heart disease, stroke, and nonvascular mortality. JAMA. 2009;302:412-23.

\section{Submit your next manuscript to BioMed Central and we will help you at every step:}

- We accept pre-submission inquiries

- Our selector tool helps you to find the most relevant journal

- We provide round the clock customer support

- Convenient online submission

- Thorough peer review

- Inclusion in PubMed and all major indexing services

- Maximum visibility for your research

Submit your manuscript at www.biomedcentral.com/submit
C Biomed Central 